\title{
BMJ Global Health Assessment of the implementation fidelity of the Arctic Char Distribution Project in Nunavik, Quebec
}

\author{
Lara Gautier, ${ }^{1,2,3}$ Catherine M Pirkle, ${ }^{4}$ Christopher Furgal, ${ }^{5}$ Michel Lucas ${ }^{6,7}$
}

To cite: Gautier L, Pirkle CM, Furgal C, et al. Assessment of the implementation fidelity of the Arctic Char Distribution Project in Nunavik, Quebec. BMJ Global Health 2016;1: e000093. doi:10.1136/ bmjgh-2016-000093

Received 19 May 2016 Revised 6 July 2016 Accepted 21 July 2016

\section{CrossMark}

\footnotetext{
${ }^{1}$ Department of Social and Preventive Medicine, Université de Montréal, Montreal, Québec, Canada ${ }^{2}$ Public Health Research Institute, Université de Montréal, Montreal, Québec, Canada

${ }^{3}$ Centre d'Etudes en Sciences Sociales sur les Mondes Africains, Américains et Asiatiques, Université Paris Diderot-Paris 7, Paris, France ${ }^{4}$ Office of Public Health

Studies, University of Hawaii-Mãnoa, Honolulu, Hawaii, USA

${ }^{5}$ Indigenous Environmental Studies Program, Trent University, Peterborough, Ontario, Canada

${ }^{6}$ Department of Social and Preventive Medicine, Université Laval, Québec, Québec, Canada

${ }^{7}$ Population Health and Optimal Health Practices Research Unit, CHU de Québec Research Centre, Québec, Québec, Canada
}

Correspondence to Lara Gautier; lara.gautier@umontreal.ca

\section{ABSTRACT}

Background: In September 2011, the Nunavik Regional Board of Health and Social Services began supporting the Arctic Char Distribution Project (AC/DP) for pregnant women. This initiative promoted consumption of the fish Arctic char-a traditional Inuit food-by pregnant women living in villages of Nunavik, an area in northern Quebec (Canada) inhabited predominantly by people of Inuit ethnicity. This intervention was intended to reduce exposure to contaminants and improve food security in Inuit communities.

Methods: We assessed the project's implementation based on data collected from background documentation, field notes and qualitative interviews with project recipients and implementers. Themes emerging from the data are critically discussed in the light of the framework for implementation fidelity developed by Carroll et al in 2007.

Results: Pregnant women fully embraced the initiative because of its cultural appropriateness. However, project implementation was incomplete: first because it did not cover all intended geographic areas, and second because of a recurring inconsistency in the supply and distribution of the fish. In addition, the initiative has been inconsistently funded and relies on multiple funding sources.

Discussion: This work highlights the extent to which project complexity can impede successful implementation, particularly in terms of communication and coordination. We provide recommendations for improving project implementation and suggest amendments to the implementation fidelity framework.

\section{BACKGROUND}

Sixty years of dramatic socioeconomic and environmental changes have affected northern Canadian indigenous communities, with negative impacts on many indigenous food systems. Inuit communities in Canada have the highest recorded levels of food insecurity of any indigenous population in an industrialised country. ${ }^{1}$ Across northern Canada, an estimated $50 \%$ of indigenous households are experiencing moderate to severe food insecurity. $^{1-5}$

\section{Key questions}

What is already known about this topic?

- Nutrition interventions are instrumental in improving public health, especially in Inuit communities, which are particularly vulnerable to food insecurity and its consequences.

- In addition, compared with southern Canadians, certain Inuit populations are disproportionately exposed to mercury.

- Evaluation of health promotion activities that build on Inuit food systems while reducing exposure to environmental contaminants is needed.

\section{What are the new findings?}

- The Arctic Char Distribution Project's implementation was successful in terms of recipients' acceptance.

- There were, however, many logistical and organisational challenges impeding its full implementation.

- The 2007 framework for implementation fidelity proved useful in assessing a culturally appropriate public health intervention that was implemented in a specific context (ie, Inuit-populated areas of Canada).

\section{Recommendations for policy}

- This work highlights the extent to which logistical and organisational complexity can impede successful project implementation, even of a relatively simple intervention.

- Examination of implementation fidelity is of particular interest in the field of indigenous health because of limited evaluation research, especially in northern Canada, where this research took place.

- Given the importance of coordination and communication for project sustainability, it is strongly recommended that policymakers consider implementing formal coordination guidelines and appointing project coordinators for each key institution involved in public health projects similar to this one.

The National Aboriginal Health Organization acknowledges that nutrition interventions are cornerstones for improving 
public health, especially in Inuit communities, which are particularly vulnerable to food insecurity and its consequences. ${ }^{5-7}$ There is evidence that nutritional health promotion activities are associated with improved health in indigenous populations. ${ }^{68}$

Inuit food systems rely on a combination of locally harvested country and imported market foods within a context of relatively low incomes and changing cultural values. $^{9}$ Reduced reliance on country foods and increased consumption of market foods, often poor in nutritional quality, is associated with greater prevalence of chronic disease. ${ }^{10} 11$ Moreover, micronutrient deficiencies are highly prevalent in many Inuit communities. ${ }^{5} 712$

In addition to food insecurity and inadequate nutrition, exposure to environmental contaminants such as mercury threatens food safety. ${ }^{13}$ Inuit populations, whose diet traditionally includes marine mammals, are disproportionately exposed to mercury compared with southern Canadians. ${ }^{14}$ Mercury in its various forms is particularly harmful to the developing fetus and has long-term negative implications for child development. $^{15-17}$

Health promotion activities that build on Inuit food systems while reducing exposure to environmental contaminants are needed. Many country foods (eg, lake trout, beluga meat) contain high levels of nutrients, but can also have elevated mercury concentrations. ${ }^{18}$ One intervention possibility is to promote the consumption of country foods that are nutritionally rich but low in contaminants, such as Arctic char (Salvelinus alpinus), referred to as char in this paper. ${ }^{13}$ Char is a cold-water fish in the Salmonidae family. Previous studies have demonstrated that promoting country foods can lead to improved nutritional status of Inuit populations; ${ }^{19}$ however, the problem lies in the financial burden for households. Indeed, Inuit populations face low rates of employment and income, while the cost of procuring country food items has skyrocketed. ${ }^{20}$

\section{The way forward? Assessing the implementation of the Arctic Char Distribution Project}

In Nunavik, there is a community-based initiative that distributes char for free to pregnant Inuit women to improve dietary adequacy, reduce food insecurity, and minimise exposure to environmental contaminants. It is known as the Arctic Char Distribution Project (AC/DP). In the early 2000s, the initiative was piloted in three Nunavik communities. In subsequent years, attempts were made to scale-up the initiative to all villages along the Hudson Bay coast (figure 1). ${ }^{20}$

In September 2011, 10 years after its first iteration, the Inuulitsivik Health Centre, with funding from the Nunavik Regional Board of Health and Social Services (NRBHSS), reinstated the initiative. It is important to note that it was not a formal public health programme with a structured administration and secured resources and thus was distinct from other formally implemented programmes or interventions. We therefore refer to the initiative as the $\mathrm{AC} / \mathrm{DP}$. In theory, this project was quite simple. Char was fished by local fishermen along the

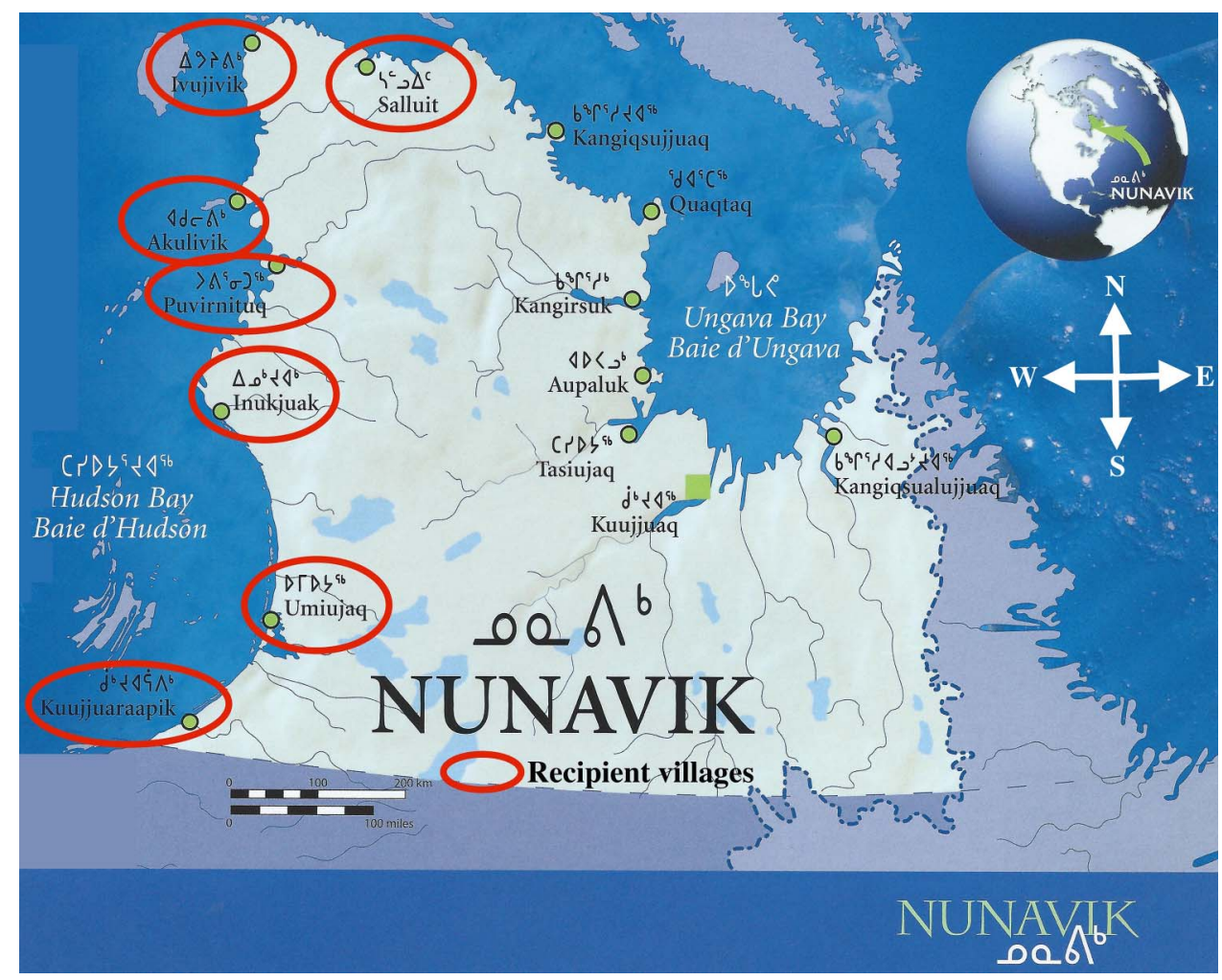

Figure 1 Map of Nunavik. Source: adapted from http://www.inuitfirstcanadians.com/2014/02/28/250/. Courtesy of InuitFirstCanadians.com, 2014. 
Hudson Bay coast of Nunavik and sold slightly below the market price to the NRBHSS. It was then put in large freezer boxes to avoid freezer burn. The boxes were then transported by plane using the regional airline (Air Inuit) to the coastal villages. Technically, the boxes were shipped for free, and the airline brought back the empty boxes to the originating communities providing the char for \$C25 each. Staff in the nursing stations of the recipient villages organised the delivery of fresh fish to pregnant women in each community. Through radio advertising, pregnant women were called to pick up their fish. In smaller villages, the fish was dropped off directly at each woman's house. Once a week, all pregnant women were supposed to receive one 24 inch or larger fish to supplement their diet during pregnancy. This initiative was intended to reduce exposure to environmental contaminants, as well as improve food security and nutrition. Here, we investigate the extent to which the $\mathrm{AC} / \mathrm{DP}$ achieved its original purposes over the nearly 15 years since implementation.

As the field of process evaluation expands, new approaches have emerged for more in-depth exploration of the degree of implementation. This qualitative study adapted an innovative framework for implementation evaluation. ${ }^{21}$ Carroll $e$ e $a l^{21}$ suggest that the way in which projects are implemented may differ significantly from the original intentions of the project designers; this gap is known as 'implementation fidelity'. According to the authors-and others ${ }^{22}$ - evaluation of implementation fidelity is important because: (1) the degree to which a project is implemented may affect the association between an intervention and its outcomes; (2) assessment of fidelity may prevent false conclusions about a project's effectiveness; and (3) assessment of fidelity can identify facilitators and barriers to project uptake, acceptance and sustainability. Ultimately, lessons learnt from such evaluations provide useful ideas for adjusting and improving ongoing project delivery.

\section{METHODS}

Conceptually, implementation fidelity includes indicators of intervention (or project) adherence (content, coverage, frequency and duration), as well as moderators that may influence the degree of implementation (intervention complexity, facilitation strategies, quality of delivery, and participants' responsiveness to the intervention). ${ }^{21}$ We adapted the framework of Carroll et $a l^{21}$ for assessing implementation fidelity to the context of the AC/DP (figure 2). Within this framework, when considering participants' responsiveness, we use the concept of 'embracing relatedness' which has been applied by McCalman $^{23}$ within other indigenous contexts. Embracing relatedness is composed of: 'relatedness to self (purpose, spiritual and cultural values and beliefs, leadership, principles, capacity, and control) other organisations (partnerships, networks including family and other informal networks); and the structural conditions inherent within situations of project transfer (leadership, government policies, accountabilities, and resources, particularly funding)' ( p5).

However, Hasson ${ }^{24}$ found that Carroll et al s framework does not encompass the political, socioeconomic, cultural and environmental context in which the project is implemented. We therefore created an additional theme reflecting the various dimensions hypothesised to affect

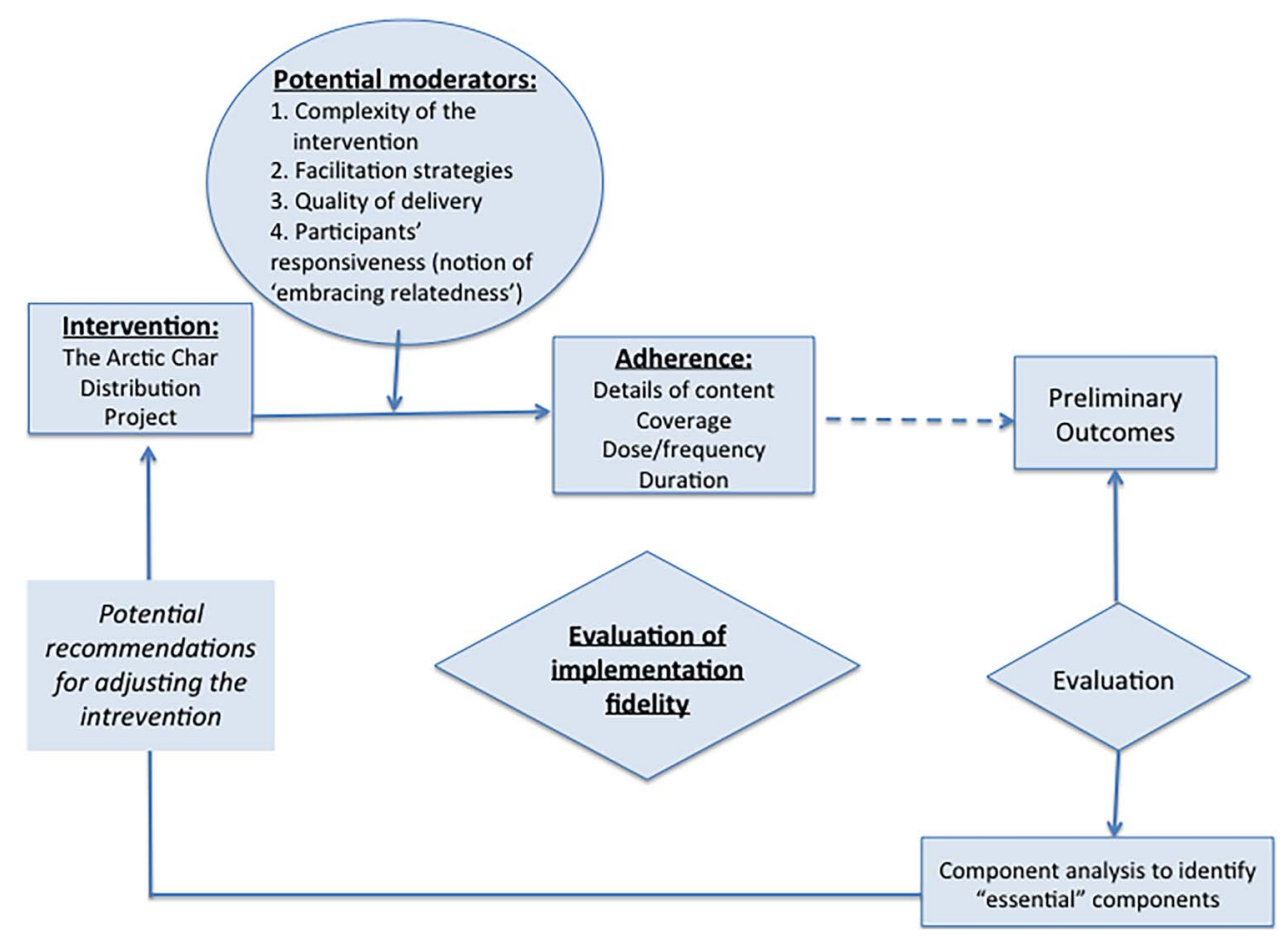

Figure 2 Conceptual framework for assessing implementation fidelity. Source: adapted from Carroll et al. ${ }^{21}$ 
project implementation entitled 'values associated with the intervention'.

We assessed the AC/DP implementation based primarily on data collected from semistructured qualitative interviews conducted with project recipients and implementers. Two sets of semistructured key informant interviews were conducted. The first were held in recipient villages along the Hudson Bay coast from February to October 2014 by a research nurse; questionnaires were developed for collecting end users' (women participating in the $\mathrm{AC} / \mathrm{DP}$ ) insights and perspectives on the project. Women from each participating village were interviewed in English (but with translation assistance if needed). We included a range of ages, as well as parity levels (eg, first pregnancy and multiple pregnancies) to ensure internal diversification. In addition, two senior representatives from the NRBHSS, a former project coordinator, and the research nurse who interviewed project recipients were also interviewed (by the first author of this paper). All interviews were digitally recorded and transcribed.

Project documentation, observational notes and informal discussions with implementers and coordinators, email exchanges between the authors of this study and the research nurse who performed the interviews with the pregnant women, and minutes from quarterly Nunavik Nutrition and Health Committee (NNHC) meetings all supplemented interview data. Information from primary and secondary sources was triangulated and any inconsistencies resolved by returning to the interviewees for clarification. Table 1 summarises the data sources.

As mentioned above, two interview guides (available on request) were developed: one for recipients of the $\mathrm{AC} / \mathrm{DP}$ (exploring their adherence and acceptance), and one for project decision makers and implementers (seeking insights around the vision, funding, operationality and long-term sustainability of the initiative). A standard approach to coding qualitative data was used. ${ }^{25}$ Before precoding was undertaken, a codebook was developed, identifying seven main themes directly drawn from the conceptual framework to categorise codes. Precoding and coding were performed independently by the first and second authors, and codes were reviewed

Table 1 Data sources

\begin{tabular}{ll}
\hline Data source & Description \\
\hline $\begin{array}{l}\text { Key informant } \\
\text { interviews }\end{array}$ & $\begin{array}{l}13 \text { transcripts-interviews with 14 } \\
\text { pregnant women (1 interview included 2 } \\
\text { women) }\end{array}$ \\
& $\begin{array}{l}4 \text { transcripts-interviews with decision } \\
\text { makers and implementers }\end{array}$ \\
Textual & $\begin{array}{l}7 \text { transcripts-observation notes, } \\
\text { meeting minutes and project } \\
\text { documents }\end{array}$ \\
& 6 email exchanges \\
\hline
\end{tabular}

collaboratively. Potential themes were discussed in the light of the aims of the research, and agreed on through consensus.

The NNHC provided feedback, advice and guidance on the project at multiple points in time. The NNHC is a multistakeholder group in the region including both Inuit and non-Inuit community, health professional and research representatives. At each step, our work was presented to their representatives, reviewed and commented on by their members.

\section{Ethical considerations}

Ethics approval was obtained from the ethics committee of CHU de Québec Research Centre, and participants' informed consent was obtained before interviews. In exchange for the time of the pregnant women's participation, a \$C40 food coupon was provided. The additional four decision makers/implementers sent their consent by email; they did not receive any compensation.

\section{RESULTS}

Below we present the results by theme, reflecting each component of Carroll et $a l$ s framework.

\section{Intended impact of the intervention}

When a project is conceived, objectives are usually laid out before implementation. ${ }^{26}$ In the case of the $\mathrm{AC} / \mathrm{DP}$, the objectives were not clear to all the stakeholders even after several years of operation. Results showed that the major actors of the initiative lacked a common vision regarding its intended impact.

The initiative emerged from the mobilisation of several Inuit women on the Hudson coast:

[The female initiative coordinator in village $\mathrm{X}$ ] felt that fish was the best thing for pregnant women. (Notes about the AC/DP, May 2014)

In 2002-2003, concerns about environmental contaminants in pregnant women were emerging at the NRBHSS. Char's potential to reduce exposure to mercury was particularly salient in policymakers' discussions. An NRBHSS member highlighted that the objective pursued by the initiative was to:

Promote traditional food in order to improve pregnant women's nutritional status but as much as possible doing so by decreasing contaminants' levels in pregnant women. (NRBHSS member 01)

For the communities, however, it was simply perceived as a way to reduce food insecurity in the targeted villages:

It's a part of [the Inuit] way of ensuring and taking care of those that are not able to afford food. (NRBHSS member 01) 
The recipients shared this perspective: project adherence was high among interviewees, who seemed to be happy with the provision of char simply because it meant free access to country food and therefore reduced food insecurity. Ten out of 14 interviewees explicitly mentioned that the project did 'help':

It helps... when we don't have much to have, sometimes it's one of the only things to have... (Participant 11052, 21 years old)

An NRBHSS member identified two initiative goals:

It's not only providing food security, it's providing nutritional food security. (NRBHSS member 01)

In a nutshell, the AC/DP exhibited a variety of intended impacts reflecting multiple visions for why the initiative was supported, primarily food security and reducing exposure to contaminants.

\section{Intervention complexity}

Carroll et $a l^{21}$ argue that complex interventions are harder to implement. Figure 3 depicts the organisation of the $\mathrm{AC} / \mathrm{DP}$ initiative including the characteristics of the individuals responsible for different programmatic components.

NRBHSS staff and the former initiative coordinator expressed difficulties carrying out the AC/DP:

The challenge in itself really is I think the logistics and the financial part. To find people that, each week, will really make it happen: getting the fish from one village to the plane under the right conditions. Then, once it has reached another village, it must be distributed evenly to people. [...] [The region] must find funding ie, regular $[\ldots]$...(Former project coordinator)

For these interviewees, the complexity of the intervention primarily lay in its logistics and financial sustainability.

Procurement of char, a seasonal, migratory fish that is often inaccessible in the months of May, June, October and November, was unreliable:

...Char from village $\mathrm{X}$ is not available all year round. The best time for char is late July and August. [...] From October until December, the chars are far up the rivers in the lakes. This time is spawning season. Char is not available for these months. (Discussion with project coordinators in October 2013)

There are enough char left to supply fish to pregnant women this week and the next (village $\mathrm{X}$ only). [..] There is not enough char to send fish to the southern villages. (Notes about the AC/DP, May 2014)

Besides a lack of reliability in supply, transportation by plane from one village to another was often challenged by a number of practical barriers that limited effective implementation. For instance, timely shipping emerged as a key success factor for distributing fresh fish in the recipient villages:

Ideally, char is shipped early in the week to avoid it arriving at 'the Nursing' on a Friday or weekend when it could go rotten. Shipping the fish early in the week is not always possible, especially if weather is bad. When fish can be shipped, the package must be prepared and ready for noon (when the plane leaves). (Discussion with key persons $\mathrm{X}, \mathrm{Y}, \mathrm{Z}$ in village $\mathrm{X}$ in October 2013)

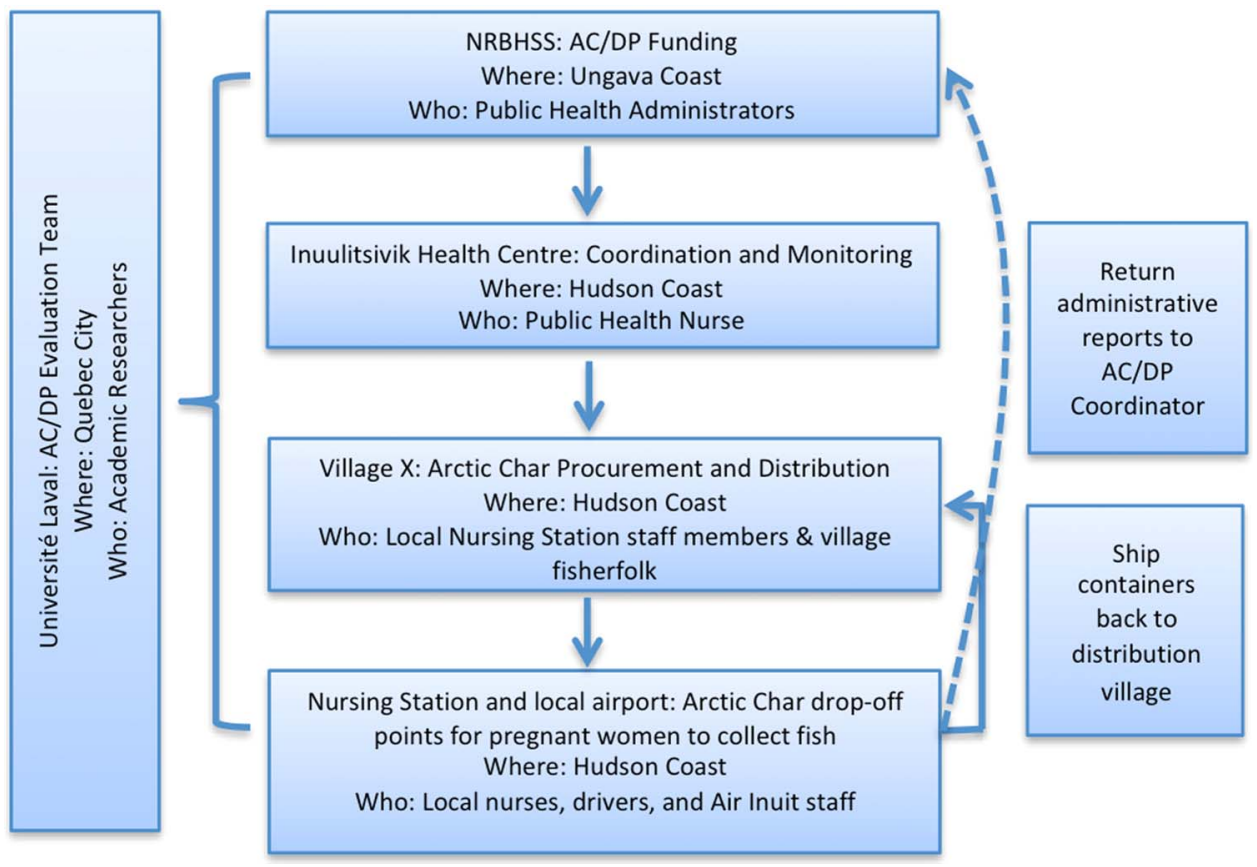

Figure 3 Organisation of the Arctic Char Distribution Project (AC/DP). NRBHSS, Nunavik Regional Board of Health and Social Services. Source: project documentation. 
Storage further complicated the process. Once it reaches the villages, the fish has to be quickly stored in the health centres. This step requires good coordination between the stakeholders:

There is a midwife who told me that the fish [...] was not good, due to the poor way storage was being managed. She told me it had been 3 days since storage had been done at Air Inuit, and the fish was still there. The refrigeration cycle had been broken. (Research nurse)

In order to sustain the supply and distribution process, boxes have to be sent back to the location of fish procurement. However, there were a number of issues throughout the process, since boxes can get lost and returning them can prove expensive.

\section{Facilitation strategies}

Carroll et al distinguish two types of facilitation strategies: support and coordination. In the case of the AC/DP, support strategies (for monitoring processes and postprocess feedback) were not easy to undertake. Post-process feedback was only sought when researchers for our study carried out interviews with the initiative implementers and end users.

An administrative document reporting who received fish was completed by health staff in the villages and returned to the initiative coordinator. However, after the departure of the initiative coordinator in January, 2014:

the administrative data has been very difficult to consistently obtain, especially after key person Y's departure.

(Personal observation notes, 2014)

The diverse chain of stakeholders necessary to procure and distribute char complicated communication. We identified various channels of communication between the different stakeholders.

Communication between implementers typically worked as follows:

Fish are provided to an appointed person in village $\mathrm{X}$, key person $\mathrm{X}$ [the initiative manager], who calls key person $\mathrm{Y}$ [the initiative coordinator] to know where to send the fish when they have a lot to share. (Notes from 19 June 2013).

Before sending the fish, key person $\mathrm{X}$ (and sometimes key person $\mathrm{Y}$ ) needs to call the recipient villages to find out the number of pregnant women. (Discussion with key persons $\mathrm{X}, \mathrm{Y}, \mathrm{Z}$ in village $\mathrm{X}$ in October 2013)

Communication for monitoring the 'post-process' was complex:

Project manager has to be reminded every delivery to fill out the paperwork regarding the pregnant women. [...] Emails are sent, but [staff members from] the Nursing Stations sometimes do not read them, so a phone call has to be made. (Table of obstacles encountered during implementation of the AC/DP -1 October 2013)
Initiative implementers communicate with end users by phone to inform them about the availability of fish:

Midwifes [call me to get]... char. (Participant 11043, 19 years old)

I call... asking if they have a fish [...] every week. (Participant 11036, 26 years old)

In a few instances, women were given explanations by the nurses or health workers on why they received char:

They tell me it's good for me and for my baby (Participant 11043, 19 years old)

Implementers also communicate with fishermen to make sure they record the number of fish that were bought for the initiative:

Typically, key person $\mathrm{Y}$ receives receipts of the money paid to the fisherman for the fish. She has a log of how many fish were sent to each village, a log of who is taking the fish, as well as why and why not.

However, there were misconceptions of the initiative by the fishermen, potentially due to a lack of understanding of its goals:

At some point [a former project coordinator] realised that the fishermen were sending char to some locations but to others they were sending whitefish...Still charging for char... Here I think it is related to the fact that people have not understood what the project was. It wasn't the health centre that was buying the fish, it was a project targeting the wellbeing of pregnant women and their newborns (NRBHSS member 02)

Problems also occurred with the transporter (Air Inuit) because of lack of communication between the different actors:

We had to explain to them that it was for the wellbeing of the pregnant women that the [midwives] had to communicate with Air Inuit in order to avoid that problems, such as rotting fish, happen again. [...] Except that in their tasks' definition, it wasn't specified... (Research nurse)

Communication between implementers, particularly the midwives, who were in charge of distributing the fish, and NRBHSS members was also challenging:

[In village Y,] the midwives had no idea why there had been no shipments of fish. They had no communication about the project and did not know who coordinated it. [...] (Notes about the AC/DP, May 2014)

The irony is that the project is coordinated out of [village Y] in the same building as where these [health] workers are, just in another unit. (Personal observation notes, 2014) 


\section{Quality of delivery}

The quality of coordination efforts has obvious effects on the quality of initiative delivery. As noted above, insufficient communication between the implementers and transporters was a barrier and affected the freshness and edibility of the fish. This is illustrated by the following comment:

[...] It's the taste. [..] I could tell that it's been sitting around for a while. (Participant 11052, 21 years old)

Yet overall, it appears that the project recipients were fairly happy about the freshness of the char. Indeed, more than half of our interviewees noted that the fish was fresh when they picked it up at the nursing station or received it at home.

Other attributes of the initiative were highly appreciated, in particular the ability to choose the size of the fish, its taste and its nutritional attributes:

There were big and small fishes. [...] They were bigger ones but the middle ones... look yummy! (Participant 11045,33 years old)

\section{Participants' responsiveness to the intervention}

Individual end users' embracing relatedness with the intervention

We investigated the degree to which pregnant women embraced the $\mathrm{AC} / \mathrm{DP}$ as measured by the understanding, acceptance and values related to the project among participants and their social networks.

Despite communication and logistical difficulties, acceptance of the project was high: 13 out of the 14 end users asserted that they liked the intervention.

[Arctic char], it's my favourite! (Participant 22064, 35 years old)

At least six interviewees stated that they wanted a more frequent distribution of the project. Two women mentioned appreciating the initiative because of the convenient delivery:

Especially when we don't have any transportation to go hunt for it or go fish for it. It's nice. (Participant 11045, 33 years old)

When I breastfeed, I want country food, give me country food... (Participant 11053, 24 years old)

Beneficiaries systematically shared the food with all the members of their family, and sometimes with relatives and neighbours, a common practice in Inuit culture:

I share with my family and my friends. (Participant 22085, 21 years old)

These elements stress the initiative's acceptance among pregnant women because they culturally embraced it.

\section{Organisational responsiveness}

The initiative involved a network of partners that included the NNHC, the Inuulitsivik health centre, the communities, and the fishermen's and hunters' associations. Interviews with members of the NRBHSS and a former project coordinator showed that acceptance by each of these partners was key to the effective distribution of char:

We had arranged with hunters and fishermen when they fish to deliver in communities where there was no fish because not all communities have access to char. (Former project coordinator)

The initiative appeared to be well accepted in recipient communities (in particular, communities in villages V, X, Y and Z).

The participation was very good in the communities [...]. The communities that we worked with were very collaborative. (NRBHSS member 01)

Staff from the nursing stations also liked the idea that the AC/DP encouraged country foods. However, several implementers expressed concerns:

The [village Y's] [health] workers complained that the Project was too slow, that they did not get enough char. [...] They highlighted that during the winter was when they most needed the Project, 'That is when we lack food.' (Head midwife's quote, in Notes about the AC/DP, May 2014).

Engaging dedicated people and adequate communication were raised as key concerns:

Finding people that will really make sure that the fish goes from a village by plane to get to the other in the right conditions, [that is where the challenge lies]. (Former project coordinator)

If we really wanted to relaunch [the project], make it more effective, I think we should have a communication plan and a mobilisation plan for all the partners involved. (NRBHSS member 02)

\section{Structural responsiveness}

Structural factors (in particular, leadership and accountability of the different actors, human resources involved, and funding) also affect the fidelity of project implementation.

First, the commitment to the initiative and therefore the leadership of the top-level administrators was unstable, and confusion prevailed:

[...] when I was leading the committee, all the resources in place, there was collaboration. [After I left,] I think it became a problem of leadership. (NRBHSS member 01)

...even though our membership in the [NNHC] Committee is quite wide and fairly representative of 
organisations of the region, $[\ldots]$ you make decisions but it looks like they do not report to their organisation. (NRBHSS member 02)

In addition, the level of awareness about the funding of the initiative among the policymakers at the NRBHSS was not always optimal:

I have no idea how it's funded now. [...] Because all I was to ensure was that the project was undergoing and that there was money. (NRBHSS member 01)

Another type of confusion was evident at the implementation stage, with midwives having 'no idea why there had been no shipments of fish and who was running the project' (Personal observation notes, 2014). Interviews and observations indicated that many of the nursing stations' staff in villages $\mathrm{X}$ and $\mathrm{Y}$ assumed that most of the responsibilities were to be held by thirdparty coordinators.

The variety of human resources needed for the initiative also contributed to the complexity of the implementation, essentially because Nunavik is known to be a region where employee turnover is fairly high:

And people change too, there is a high turn-over. [...] midwives changed. Because midwives were very key to the success of this project. (NRBHSS member 01)

Turnover affects all sectors of Nunavik administration and economy, including at the NRBHSS (there has been as many as four different coordinators of the $\mathrm{AC} / \mathrm{DP}$ over 10 years), in health centres, and at Air Inuit:

Every time there was an employee of Air Inuit who was leaving, we had to start from scratch and again inform him [about the specific case of char]. (NRBHSS member 02).

The high reliance on individuals who tend to change jobs very often was found to be detrimental by decision makers as well. One NRBHSS representative suggested that we engage all stakeholders in some sort of forum, to 'convince them that it is a priority project and bring them into the process' (NRBHSS member 02).

The initiative has been inconsistently funded and relies on multiple funding sources. This raises concerns about stability:

[At the beginning] I think the funding was being geared toward the Canadian prenatal program. [...] And the NNHC through its partners-the hunting support, as well as the establishments that were managing it, as well as public health funds on the nutritional side-these were all part of the funding. (NRBHSS member 01)

\section{Project adherence}

The last component in Carroll et als framework is the ultimate adherence to the intervention-that is, programme coverage, frequency and duration.
Coverage: geographical areas and populations effectively covered by the intervention

The fish was supposed to be distributed evenly across all the villages:

[...] We were working with municipalities that had char and organising them to ship to communities that did not have char. And we worked with our community health workers in promoting the distribution and the availability of char. (NRBHSS member 01)

However, from the beginning and throughout the project, geographic inequity emerged as an important issue:

[The project manager in village $\mathrm{X}$ ] did bring up some barriers to project implementation [...] She highlighted that it is hard to obtain enough fish to send to the southern villages. (Notes about the AC/DP, May 2014)

\section{Frequency: consistency of the distribution of char}

As noted above, the fish provision was unstable over time and distribution was inconsistent. For instance, in May 2014 one of the members of our research team noted that:

Every week the women come to the nursing station to look for fish, but there has not been fish for a while. (Notes about the AC/DP, May 2014)

\section{Duration: timeframe and stability of the intervention}

We already attempted to implement [the project] about 15 years ago. [...]. Then after a few years, at some point it was stopped. (Former project coordinator)

In October 2013, there were concerns among the initiative coordinator, manager and participants that fish would not be obtained in the upcoming months.

One important consideration of the char project is that the resource can be unreliable. [...] As char is not reliable, this could have aggravated food insecurity. (Notes from 19 June 2013)

The environmental sustainability of the resource has also raised concerns:

The size of the char that are being caught appears to be smaller and smaller with time. Key person $\mathrm{X}$ thinks that there are too many fishermen. (Discussion with key persons $\mathrm{X}, \mathrm{Y}, \mathrm{Z}$ in village $\mathrm{X}$ in October 2013)

These results demonstrate incomplete implementation of the initiative: first because it does not cover all intended areas, and second because of a recurring inconsistency in the supply and distribution of the fish. Box 1 summarises the strengths and weakness of the $\mathrm{AC} / \mathrm{DP}$ implementation as assessed through the framework of Carroll et al. ${ }^{21}$ 
Box 1 Strengths and weaknesses of the Arctic Char Distribution Project implementation

Strengths

- Appreciated and desired by end users

- Culturally relevant for recipient communities (ie, reference to 'country food')

- Nutritionally rich

- Low in contaminants

- Accepted by most health workers

- Relatively inexpensive

Weaknesses

- Complexity of logistics (ie, inconsistency of transportation distribution channels) for ensuring delivery of fresh fish to project recipients

- Communication and coordination challenges among the different implementers

- Long-term financial sustainability

- High turnover of human resources impeding long-term implication of implementers

- Seasonality of char (unavailable at certain periods of the year)

Char vulnerable to overexploitation

\section{Values associated with the intervention}

Many of the interviews highlighted specific values, referring to the context in which projects are implemented.

\section{Community-based value}

The idea of providing free fish to pregnant women in need did not come from Health Canada or any federal initiative:

[i]t was a Nunavik programme, it came from people that cared about the wellbeing of the newborn child and the health of the mother. (NRBHSS member 01)

Public health value: improving nutritional status and food security

The initiative was able to promote public health among pregnant women in Nunavik through the improvement of nutritional status:

It was like, clear that char was a fish that had excellent nutritional properties, with very few contaminants. (NRBHSS member 02)

and reducing food insecurity:

Knowing the problems of food insecurity, it is something, to ensure the provision of an arctic fish to a woman.

(Former project coordinator)

\section{Reference the target population}

Policymakers and implementers highlighted the specificity of the initiative to its target population.

It's a very specific project targeting a risk group. [...] [It] ensure[s] that pregnant women eat nutritional clean food. (NRBHSS member 02)
In turn, beneficiaries often claimed their right to get the fish because of their pregnancy.

Traditional values: reinforcing country food in diets

The initiative was perceived by community members as a way to reinforce the importance of country foods.

[The elders] tell us that... country food is better than store food. (Participants 11032 (43 years old) and 11033 (22 years old))

Links with 'the elders'

If older generations recommend eating fish during pregnancy, then women often thought they should eat it.

[The elders] say that... fish is good for the baby in you. (Participant 11036)

Recommendations and strong support from elders regarding the consumption of fish during pregnancy, in turn, provides the intervention with strong cultural legitimacy.

\section{DISCUSSION}

Results from this assessment of project implementation demonstrate the high degree of cultural acceptability of the AC/DP in Nunavik. Unfortunately, the complexity of the project has impeded its successful implementation.

\section{Coordination and communication difficulties}

Logistics (transportation, shipping, storage, distribution) necessary for implementation of the AC/DP require a high level of coordination between stakeholders, such as community-based nurses and transporters, as the fish is perishable. Lack of commitment by some stakeholders has contributed to implementation difficulties, as has the high turnover of staff. The staff of Air Inuit and the nursing station frequently changed, and the AC/DP coordinators often changed positions. This prevented the development of long-term coordinated networks of committed people willing to overcome the logistical challenges of resource distribution in a remote region. In turn, this adversity affected $\mathrm{AC} / \mathrm{DP}$ reliability, with pregnant women and other stakeholders often unsure about fish availability.

Structural issues contribute to the lack of communication between pivotal stakeholders-in particular, project coordinators and nurses-even when working in close proximity. Challenged communication was also identified in the implementation evaluation of another nutrition intervention, the Nutrition North Canada Program. ${ }^{27}$ However, evaluation of this type of initiative is scarce in northern Canada. Investigation of this phenomenon in other health promotion projects in remote regions should be pursued in future research.

In addition, reporting practices and feedback about the initiative have been inconsistent-for instance, the 
idea of using 'distribution forms' to monitor transport boxes was unpopular among the implementers and coordinators. The lack of consistent reporting practices hampered efforts to understand bottlenecks in project implementation. Without reliable statistics about intervention coverage (eg, the number of women receiving fish and the frequency of fish distribution), coordinators struggle to develop stable plans. More fundamentally, without these metrics, successes cannot be verified and reported to project funders, actors and beneficiaries. This is a lost opportunity to reinforce the engagement of those who procure, distribute and coordinate $\mathrm{AC} / \mathrm{DP}$ activities.

\section{Lack of clarity about the vision of the project}

Different $\mathrm{AC} / \mathrm{DP}$ actors understand the initiative vision quite differently. For example, initiative administrators in Kuujjuaq envision the project as a health promotion tool to reduce exposure to mercury with incidental beneficial effects on food security, whereas procurers/ implementers have described the primary aim as providing fish to pregnant women. The beneficiaries value the project for increasing food security by bringing desired country foods back into their diets.

The lack of a common vision has, in our opinion, diffused the responsibility among stakeholders. Equal commitment toward reaching a common objective among implementers is key to the success of the intervention. There were various instances where it appeared that stakeholders were not willing to take the lead in investigating sources of distribution problems. Nursing station staff often relied on initiative coordinators and others in positions of authority to solve logistical issues. Officials also demonstrated limited engagement through lack of understanding regarding $\mathrm{AC} / \mathrm{DP}$ funding and insufficient reporting of outcomes from NNHC meetings to critical institutions.

The accountability of all stakeholders to project recipients was therefore challenged by a lack of clear leadership. The evaluation of the food-subsidy programme, Nutrition North Canada, also criticised implementers for not being fully accountable to consumers (ie, need for transparency on retailers' pricing before and after the application of the subsidy). ${ }^{28}$

\section{Recommendations/suggestions for improving the project}

Given the importance of coordination and communication for project sustainability, it is strongly recommended that policymakers consider implementing formal coordination guidelines and appointing project coordinators for each key institution involved in the project. An NRBHSS member indicated that a way to engage the communities in the leadership of the project would be to assign the entire management of the project over to them. This can be accomplished by encouraging local involvement in development, selection, and training on the use of project-reporting tools. Indeed, engaging local agents in reporting activities enables dissemination of project effectiveness. ${ }^{29}$ The structural issue of employee turnover would remain, but would be somewhat attenuated by more efficient training and service delivery. Community meetings, involving representatives of key institutions and AC/DP recipients, to reach consensus on initiative purpose and goals could increase leadership and a sense of project ownership among stakeholders.

Pregnant women interviewed expressed a strong interest in understanding the project's purpose and the nutritional value of the fish to them and their babies. As such, it is recommended that community nurses take the opportunity provided by the AC/DP for contact with pregnant women to engage in health promotion activities such as providing nutrition consultation.

Finally, as there are some concerns about the environmental sustainability of sourcing char solely from river and lake systems along the Hudson Coast, we recommend considering other sourcing options, including those systems along the Ungava Coast, where some report important stocks of char; however, collaborations with local fishery experts are needed to prevent unintended overexploitation of the resource.

\section{Value of the framework for the char project case}

The framework proved useful for systematically assessing barriers and facilitators to project implementation. A weakness of the framework, as also noted by Hasson, ${ }^{24}$ is the insufficient attention to the sociopolitical and environmental context around project implementation. This emerged in the interviews through concerns about the financial and environmental sustainability of the initiative.

Our results demonstrated that the initiative was supported and valued by numerous individuals. The absence of 'values' in the framework represents a technocratic vision of project implementation that seeks to balance facilitators and barriers. This ignores the necessity for motivation among those tasked with designing and implementing intervention and policies. Overall, the AC/DP does not suffer from a lack of supportive values among stakeholders, although the specific purposes were often disputed. The challenge then is to build on the support for the project to overcome logistical and communication barriers.

\section{CONCLUSION}

As the field of process evaluation expands, new approaches emerge for exploring the implementation 'black box', including the notion of implementation fidelity, which the framework of Carroll et $a l^{21}$ conceptualises. Their framework, as well as other similar enterprises, helps researchers and policymakers with effective project implementation. This is of particular interest in the field of indigenous health because of elevated complexities in implementation. There is a need to further investigate these processes to better inform decision making. 
Handling editor Valery Ridde

Twitter Follow Lara Gautier at @Lara_Gautier

Acknowledgements We would like to thank the NRBHSS and the NNHC for their continued feedback throughout the process of this research project. Our thanks also go the anonymous participants from the Hudson Coast communities, and in particular the staff at the nursing station in Akulivik for their patience and time. We also acknowledge the work of Isabelle Veillette, the research nurse who completed the first set of interviews with pregnant women. We also would like to thank Lisa Teh for her support in editing and formatting the paper. Finally, we would like to recognise Dr Éric Dewailly who passed away while this manuscript was being drafted and who was the co-principal investigator of the grant from which this study was funded. He was the visionary who first supported this pilot intervention initiative many years ago, an authority on environmental and human health in the circumpolar world, an exceptional mentor, and a brilliant mind. He is greatly missed.

Contributors LG conducted the second set of interviews, carried out thematic coding of all interviews and project documentation, and drafted the initial version of the manuscript. CMP co-conceived the study, participated in its original design and coordination, conducted field observations, carried out the coding, and provided substantial inputs to the manuscript. CF revised each version of the manuscript and provided substantial inputs to the manuscript. $\mathrm{ML}$ co-conceived the study, participated in its design and coordination, provided substantial inputs to the manuscript, and ensured the study supervision. ML had full access to all of the data in the study and takes responsibility for the integrity of the data and the accuracy of the data analysis. All authors read and approved the final manuscript.

Funding The study was supported by grants from Canadian Institutes of Health Research (CIHR) Operating Grant: Population Health Intervention Research (\#127069) and the Nunavik Regional Board of Health and Social Services (NRBHSS). The funding sources were not involved in the data collection, data analysis, manuscript writing and publication.

Competing interests Lara Gautier's current PhD thesis is supervised by Valéry Ridde who acted as Handling editor for this paper. The Handling editor was not involved in any part of the evaluation or peer-review process of this article.

Ethics approval Ethics committee of CHU de Québec Research Centre.

Provenance and peer review Not commissioned; externally peer reviewed.

Data sharing statement No additional data are available.

Open Access This is an Open Access article distributed in accordance with the Creative Commons Attribution Non Commercial (CC BY-NC 4.0) license, which permits others to distribute, remix, adapt, build upon this work noncommercially, and license their derivative works on different terms, provided the original work is properly cited and the use is non-commercial. See: http:// creativecommons.org/licenses/by-nc/4.0/

\section{REFERENCES}

1. Council of Canadian Academies. Aboriginal food security in Northern Canada: an assessment of the state of knowledge. Ottawa: The Expert Panel on the State of Knowledge of Food Security in Northern Canada, Council of Canadian Academies, 2014. http:// www.scienceadvice.ca/en/assessments/completed/food-security aspx (accessed 29 Jan 2015).

2. Egeland GM. Inuit health survey 2007-2008: inuvialuit settlement region. Centre for indigenous peoples' nutrition and environment, 2010.

3. Egeland GM. Inuit health survey 2007-2008: nunatsiavut. Centre for indigenous peoples' nutrition and environment, 2010.

4. Egeland GM. Inuit health survey 2007-2008: nunavut. Center for indigenous peoples' nutrition and environment, 2010.

5. Pirkle CM, Lucas M, Dallaire R, et al. Food insecurity and nutritional biomarkers in relation to stature in Inuit children from Nunavik. Can J Public Health 2014;105:e233-8.
6. Earle L. Traditional Aboriginal Diets and Health. Prince George, BC: National Collaborating Centre for Aboriginal Health, NCCAH 2011. http://www.nccah-ccnsa.ca/docs/social\%20determinates/1828_ $\mathrm{NCCAH}$ mini diets health final.pdf

7. Egeland GM, Pacey A, Cao Z, et al. Food insecurity among Inuit preschoolers: Nunavut Inuit Child Health Survey, 2007-2008. CMAJ 2010;182:243-8.

8. World Health Organization. Diet, nutrition and the prevention of chronic diseases. Geneva: 2002. http://www.who.int/ dietphysicalactivity/publications/trs916/en/ (accessed 12 Apr 2015).

9. Chan HM, Fediuk K, Hamilton S, et al. Food security in Nunavut, Canada: barriers and recommendations. Int J Circumpolar Health 2006;65:416-31.

10. Sheikh N, Egeland GM, Johnson-Down L, et al. Changing dietary patterns and body mass index over time in Canadian Inuit communities. Int J Circumpolar Health 2011;70:511-19.

11. Kuhnlein HV, Receveur O, Soueida R, et al. Arctic indigenous peoples experience the nutrition transition with changing dietary patterns and obesity. J Nutr 2004;134:1447-53.

12. Huet C, Rosol R, Egeland GM. The prevalence of food insecurity is high and the diet quality poor in Inuit communities. J Nutr 2012;142:541-7.

13. Van Oostdam J, Donaldson SG, Feeley M, et al. Human health implications of environmental contaminants in Arctic Canada: a review. Sci Total Environ 2005;351-352:165-246.

14. Pirkle $\mathrm{C}$, Muckle $\mathrm{G}$, Lemire $M$. Managing mercury exposure in Northern Canadian communities. CMAJ 2016;188:1015-23.

15. Boucher $O$, Jacobson SW, Plusquellec $P$, et al. Prenatal methylmercury, postnatal lead exposure, and evidence of attention deficit/hyperactivity disorder among Inuit children in Arctic Québec. Environ Health Perspect 2012;120:1456-61.

16. Jacobson JL, Muckle G, Ayotte P, et al. Relation of prenatal methylmercury exposure from environmental sources to childhood IQ. Environ Health Perspect 2015;123:827-33.

17. Karagas MR, Choi AL, Oken E, et al. Evidence on the human health effects of low-level methylmercury exposure. Environ Health Perspect 2012;120:799-806.

18. Lemire M, Kwan M, Laouan-Sidi AE, et al. Local country food sources of methylmercury, selenium and omega-3 fatty acids in Nunavik, Northern Quebec. Sci Total Environ 2015;509-510:248-59.

19. Gagné D, Blanchet R, Lauzière J, et al. Traditional food consumption is associated with higher nutrient intakes in Inuit children attending childcare centres in Nunavik. Int J Circumpolar Health 2012;71:18401.

20. Duhaime $\mathrm{G}$, Chabot $\mathrm{M}$, Fréchette $\mathrm{P}$, et al. The impact of dietary changes among the Inuit of Nunavik (Canada): a socioeconomic assessment of possible public health recommendations dealing with food contamination. Risk Anal 2004;24:1007-18.

21. Carroll C, Patterson M, Wood S, et al. A conceptual framework for implementation fidelity. Implement Sci 2007;2:40.

22. Breitenstein SM, Gross D, Garvey CA, et al. Implementation fidelity in community-based interventions. Res Nurs Health 2010;33:164-73.

23. McCalman JR. The transfer and implementation of an Aboriginal Australian wellbeing program: a grounded theory study. Implement Sci 2013;8:129.

24. Hasson H. Systematic evaluation of implementation fidelity of complex interventions in health and social care. Implement Sci 2010;5:67

25. Miles MB, Huberman AM. Qualitative data analysis: an expanded sourcebook. SAGE, 1994.

26. Pinto JK, Slevin DP. 20. Critical success factors in effective project 1264 implementation. Proj Manag Handb 1988;479:167-190.

27. Government of Canada. Implementation Evaluation of the Nutrition North Canada Program. Aboriginal Affairs and Northern Development Canada 2013. http://www.aadnc-aandc.gc.ca/eng/ 1395347953550/1395348287432 (accessed 8 Aug 2015).

28. Galloway T. Is the Nutrition North Canada retail subsidy program meeting the goal of making nutritious and perishable food more accessible and affordable in the North? Can J Public Health 2014;105:e395-7.

29. Mbwili-Muleya C, Lungu M, Kabuba I, et al. Consolidating processes for community health centre partnership and accountability in Zambia. Harare: EQUINET, 2008. http://www.equinetafrica.org/bibl/ docs/PRAequitygauge2008.pdf (accessed 17 Nov 2015). 